\title{
An inventory planning problem for time-varying linear demand and parabolic holding cost with salvage value
}

\author{
Pavan Kumar* \\ Department of Mathematics, Koneru Lakshmaiah Education Foundation \\ Vaddeswaram, Andhra Pradesh, India - 522502 \\ E-mail: 〈pavankmaths@gmail.com〉
}

\begin{abstract}
In this manuscript, a model is proposed for the inventory planning problem with items which deteriorate linearly with respect to time. The concept of salvage value for deteriorated items is considered and incorporated in this model. The solution procedure of proposed optimization model is illustrated by a couple of numerical examples. A convexity check of the average total cost function is performed by plotting a two dimensional graph. The sensitivity test of the proposed model is performed to study the effect of changing the least as well as the most sensitive parameters in the proposed optimization model. Some graphical representations are constructed to discuss the outcomes and results so obtained for a choice of various parameters.
\end{abstract}

Keywords: salvage value, no shortages, time-varying linear demand

Received: May 28, 2019; accepted: September 30, 2019; available online: December 13, 2019

DOI: 10.17535 /crorr.2019.0017

\section{Introduction}

In today's competitive and highly growing world, Inventory planning (IP) is crucial in the present competitive environment and is steadily gaining a lot of research attention. Firms and Companies are facing some challenges in determining the methods to fulfill the ever-rising customer's demand and to remain competitive in the market while keeping the total costs manageable. The demand depends on various factors like inventory level or stock, selling price, time, etc. For a particular season, there are some items like ice-cream, woolen cloths, dairyproducts, green vegetables, etc., which deteriorates over time. These items are said to be as deteriorating items. As a result of this deterioration, a fraction of items becomes obstacle. Finally, it causes the shortages in the inventory control system, which affects the total cost as for the inventory system as well as total profit also. So, the deterioration is justified to be considered as an affecting factor for the inventory control system. A model for exponentially decaying inventory system is presented in [12]. Moreover, the holding cost is also an important factor affecting the total cost of the inventory planning, and hence the total profit. The nature of the holding cost may be linear or nonlinear depending on time parameter. Various researchers have considered extending the work on inventory planning for time dependent variable holding cost. For instance, [20] proposed a variable holding cost rate EOQ model. An economic order quantity models with non-linear holding cost was studied in [29]. In real life cases, we observe that some industry or firm offer the permissible delay in payments to their clients. A retailer's pricing and lot-sizing policy for exponentially deteriorating items was suggested in [13], where they implemented the condition of permissible delay in payments.

${ }^{*}$ Corresponding author. 
An inventory control model for economic order quantity of deteriorating items under permissible delay in payments was developed in [5]. As an economic order quantity model, an inventory control system for deteriorating items with time varying demand was formulated in [7], where the partial backlogging is considered. For a single period inventory problem with quadratic demand distribution, an expression for the total cost function was modeled in [3] under the influence of market policies. The concept of trade credit financing is also a crucial factor affecting the total profit of the inventory optimization problem.

A mathematical model for the inventory optimization problem was presented in [8] to determine the optimal cycle time for exponentially deteriorating products under trade credit financing. A model for an inventory problem with deteriorating items under the condition of permissible delay in payments was proposed in [7]. The other notable contributions are in $[2,4,6,8,7]$. In literature, many researchers considered time dependent quadratic demand with or without shortages. A note on order level inventory mathematical model for a deteriorating item with time dependent quadratic demand was studied in [14]. An inventory model for deteriorating items with exponential declining demand and partial backlogging was suggested in [23]. A mathematical model for the inventory problem with stock-level dependent demand rate and variable holding cost was studied in [1]. Due to vagueness, some researchers considered the deterioration as a random variable following some known probabilistic distribution.

An EOQ model for deteriorating items with Weibull distribution deterioration, unit production cost with quadratic demand and shortages was formulated in [2]. Later, an EOQ model for a deteriorating item with time dependent quadratic demand under permissible delay in payments was modeled in [15]. Among the various patterns of demand function, the power pattern demand has wide applications $\mathrm{n}$ modeling an inventory problem. An inventory model with weibull distribution deteriorating item power pattern demand with shortage and time dependent holding cost was presented in [26]. Afterwards, some researchers introduced the concept of salvage value. Some inventory models by incorporating the concept of salvage value were studied in $[22,25]$. An economic lot-size model with non-linear holding cost was proposed in [24], where the holding cost was dependent on both the time and quantity.

In real-world scenario, the exact predictions of most of the uncertain variables and parameters are not easily available. The fuzzy goal programming was studied in [9], where an application to the field of multi-objective linear fractional inventory model was presented. A partial backlogging inventory model for deteriorating items with time-varying demand and holding cost was suggested in [10] by using an interval number approach. A partial backlogging inventory model for deteriorating items with time-varying demand and holding cost was developed in [11]. A multi-objective linear fractional inventory model of multi-products with price-dependant demand rate is formulated in fuzzy environment in [16]. An investigation of two-warehouse inventory problems in interval environment was presented under inflation via particle swarm optimization in [4]. The unavailability of correct data in real-world scenario results the uncertainty in demand rate. This challenges significantly for modeling an appropriate inventory control model. Over the last few decades, a huge number of research articles have published the multi criteria decision making (MCDM) methods in inventory planning problems. The fuzzy approaches for some MCDM methods in inventory control models were suggested in [17]. For two parameters Weibull deterioration and declining demand under shortages, an inventory model was developed in [22].

An inventory optimization model with variable holding cost and partial backlogging was formulated under interval uncertainty by applying the global criteria method in [18]. There are different trade credits, which a firm or industry can offer to its clients. Some inventory models for stock-dependent demand and time varying holding cost under different trade credits was modeled in [27].

An EOQ model with quadratic time-sensitive demand and parabolic-time linked holding cost was formulated in [28]. A model for inventory optimization model for quadratic increasing 
holding cost and linearly increasing deterministic demand was presented in [19]. In this article, we study a deterministic inventory planning problem for time-varying linear demand and parabolic time dependent holding cost with salvage value. Our aim is to determine the optimal total inventory cost. In short, the remainder of this manuscript is designed to organize as cited bellow. In the section 2, we discuss a list of notations used and assumption undertaken. Following the section 3 , we develop a mathematical optimization model of the proposed inventory control problem. In the section 4, we give an algorithm for the proposed model. In section 5 , some numerical experimentation is carried out. Following the section 6 , we discuss some particular cases. The sensitivity test and graphical representations are recorded in section 7 . The observations and discussions are presented in section 8. In the last, we conclude and give some future research scope in the section 9.

\section{Notations, assumptions and holding cost justification}

The proposed model is presented under the following assumptions and notations:

\subsection{Notations}

\begin{tabular}{|c|c|c|c|}
\hline Symbol & Meaning & Symbol & Meaning \\
\hline$C_{1}(t)$ & $\begin{array}{c}\text { holding cost } \\
\text { for per unit per time unit } \\
\text { purchasing }\end{array}$ & $Q$ & $\begin{array}{c}\text { order quantity } \\
\text { holding cost } \\
\text { for a cycle } \\
\text { cost per unit } \\
C_{3}\end{array}$ \\
$\begin{array}{c}\text { order cost per } \\
\text { order }\end{array}$ & $C_{H}$ & $C_{D}$ & $\begin{array}{c}\text { cost of } \\
\text { deterioration for a cycle } \\
\text { average total }\end{array}$ \\
$\theta$ & deterioration & $A T C$ & $\begin{array}{c}\text { cost per unit time per cycle } \\
\text { level of }\end{array}$ \\
$\eta$ & duration of a cycle & $I(t)$ & inventory during interval [0, T] \\
& salvage & $R(t)$ & Demand rate \\
\hline
\end{tabular}

Table 1: List of notations

\subsection{Assumptions}

1. A deterministic inventory system with single type of item only is considered.

2. No shortages are permitted.

3. Infinite planning horizon, and hence zero lead time is considered.

4. All replenishment cycles are identical. Therefore, only a typical planning cycle of timelength $T$ is discussed. Thereby, the planning horizon is the interval $[0, T]$.

5. Demand rate $R(t)$ is deterministic as well as linearly increasing function of time, and defined by the expression (for some constants $a>0$, and $b>0$ ):

$$
R(t)=a+b t
$$


6. Deteriorating rate $\theta, 0<\theta<1$, is assumed to be a constant, starts as soon as the items are received in the inventory. Also, the deteriorated items are not allowed to repair or replace during the entire cycle time.

7. For salvage value, we apply the concept as adopted by [21, 25]. Salvage value per unit, is equal to $\eta C_{2}, 0 \leq \eta<1$, and is associated with the deteriorated items.

8. As assumed by $[28,19]$, the holding cost is parabolic function of time, and defined by the following expression (for some constants $h>0, g>0$ ):

$$
C_{1}(t)=h+g t^{2} .
$$

\subsection{Justification for taking parabolic holding cost}

Holding cost is related to various costs, for example, space of the ware house, insurance, protection, cost of capital tied up, etc. Also, it can be considered as function of multiple causes. Holding cost depends on various causes. All these causes may occur at a time. Linear timedependence of holding cost implies a uniform change in the holding cost of the item per unit time. This is rarely observed to happen in the real market system. Moreover, an exponentially time-varying holding cost also appears to be unrealistic, since an exponential rate of change is very high and it is doubtful whether the holding cost of any item may undergo such a high rate of change as exponential. An alternative as well as more realistic idea is to take the parabolic time-dependent holding cost which may express all types of time-dependence depending on the signs of the parameters of the time-parabolic holding cost. Thus, it is justified to consider the time-dependent parabolic holding cost.

\section{Mathematical model formulation}

The level of inventory depletes as a result of the market demand as well as the deterioration. The shortages are not permitted. The governing differential equation is as follows:

$$
\frac{d I(t)}{d t}+\theta I(t)=-(a+b t), 0 \leq t \leq T
$$

with boundary condition $I(t)=0$ at $t=T$. Solving equation (1) and then applying the boundary condition, we obtain

$$
I(t)=\left(a-\frac{b}{\theta}\right)\left(\frac{e^{\theta(T-t)}-1}{\theta}\right)+\left(\frac{b T}{\theta}\right) e^{\theta(T-t)}-\frac{b t}{\theta},
$$

and, the order quantity:

$$
Q=I(0)=\left(a-\frac{b}{\theta}\right)\left(\frac{e^{\theta T}-1}{\theta}\right)+\left(\frac{b T}{\theta}\right) e^{\theta T}
$$


Holding cost per cycle:

$$
\begin{aligned}
C_{H} & =\int_{0}^{T} C_{1}(t) I(t) d t \\
& =\int_{0}^{T}\left(h+g t^{2}\right)\left\{\left(a-\frac{b}{\theta}\right)\left(\frac{e^{\theta(T-t)}-1}{\theta}\right)+\left(\frac{b T}{\theta}\right) e^{\theta(T-t)}-\frac{b t}{\theta}\right\} \\
& =\left(\frac{a \theta-b}{\theta^{2}}+\frac{b T}{\theta}\right)\left\{\frac{h+g T^{2}}{\theta}-\frac{2 g T}{\theta^{2}}-\frac{2 g}{\theta^{3}}+\left(\frac{h}{\theta}+\frac{2 g}{\theta^{3}}\right) e^{\theta T}\right\} \\
& -\left(\frac{a \theta-b}{\theta^{2}}+\frac{b T}{\theta}\right)\left(h T+\frac{g T^{3}}{3}\right) .
\end{aligned}
$$

Deterioration cost per cycle:

$$
C_{D}=C_{2}\left(Q-\int_{0}^{T} R(t) d t\right)=C_{2}\left\{\left(a-\frac{b}{\theta}\right)\left(\frac{e^{\theta T}-1}{\theta}\right)+\left(\frac{b T e^{\theta T}}{\theta}\right)-\left(a T-\frac{b T^{2}}{2}\right)\right\} .
$$

Salvage value of deteriorated items:

$$
\begin{aligned}
& S V=\eta \cdot \text { Deterioration cost per cycle } \\
& S V=\eta C_{2}\left\{\left(a-\frac{b}{\theta}\right)\left(\frac{e^{\theta T}-1}{\theta}\right)+\left(\frac{b T e^{\theta T}}{\theta}\right)-\left(a T-\frac{b T^{2}}{2}\right)\right\} .
\end{aligned}
$$

Average of total cost per unit time per cycle:

$$
\begin{aligned}
A T C & =\frac{1}{T}[\text { Ordering Cost }+ \text { Holding Cost }+ \text { Deteriorating Cost - Salvage Value }] \\
& =\frac{1}{T}\left[C_{3}+C_{D}+C_{H}-S V\right] \\
& =\frac{1}{T}\left[C_{3}+C_{2}\left\{\left(a-\frac{b}{\theta}\right)\left(\frac{e^{\theta T}-1}{\theta}\right)+\left(\frac{b T e^{\theta T}}{\theta}\right)-\left(a T-\frac{b T^{2}}{2}\right)\right\}+\right. \\
& +\left(\frac{a \theta-b}{\theta^{2}}+\frac{b T}{\theta}\right)\left\{\frac{h+g T^{2}}{\theta}-\frac{2 g T}{\theta^{2}}-\frac{2 g}{\theta^{3}}+\left(\frac{h}{\theta}+\frac{2 g}{\theta^{3}}\right) e^{\theta T}\right\} \\
& -\left(\frac{a \theta-b}{\theta^{2}}+\frac{b T}{\theta}\right)\left(h T+\frac{g T^{3}}{3}\right)-\eta C_{2}\left\{\left(a-\frac{b}{\theta}\right)\left(\frac{e^{\theta T}-1}{\theta}\right)+\left(\frac{b T e^{\theta T}}{\theta}\right)\right. \\
& \left.\left.-\left(a T-\frac{b T^{2}}{2}\right)\right\}\right] \\
& =\frac{1}{T}\left[C_{3}+\left(\frac{a \theta-b}{\theta^{2}}+\frac{b T}{\theta}\right)\left\{\frac{h+g T^{2}}{\theta}-\frac{2 g T}{\theta^{2}}-\frac{2 g}{\theta^{3}}+\left(\frac{h}{\theta}+\frac{2 g}{\theta^{3}}\right) e^{\theta T}\right\}\right. \\
& -\left(\frac{a \theta-b}{\theta^{2}}+\frac{b T}{\theta}\right)\left(h T+\frac{g T^{3}}{3}\right) \\
& +C_{2}(1-\eta)\left\{\left(a-\frac{b}{\theta}\right)\left(\frac{e^{\theta T}-1}{\theta}\right)+\left(\frac{b T e^{\theta T}}{\theta}\right)-\left(a T-\frac{b T^{2}}{2}\right)\right\} .
\end{aligned}
$$


Now, we expand the exponential term, and ignoring second and higher power of $\theta$ for small value of $\theta$, i.e., $e^{\theta T}=1+\theta T$, we obtain the approximate expression for $A T C$ as:

$$
\begin{aligned}
A T C & =\frac{1}{T}\left[C_{3}+\left(\frac{a \theta-b}{\theta^{2}}+\frac{b T}{\theta}\right)\left\{\frac{h+g T^{2}}{\theta}-\frac{2 g T}{\theta^{2}}-\frac{2 g}{\theta^{3}}+\left(\frac{h}{\theta}+\frac{2 g}{\theta^{3}}\right)(1+\theta T)\right\}\right. \\
& -\left(\frac{a \theta-b}{\theta^{2}}+\frac{b T}{\theta}\right)\left(h T+\frac{g T^{3}}{3}\right) \\
& \left.+C_{2}(1-\eta)\left\{\left(a-\frac{b}{\theta}\right) T+\left(\frac{b T(1+\theta T)}{\theta}\right)-\left(a T-\frac{b T^{2}}{2}\right)\right\}\right] .
\end{aligned}
$$

The following expression is resulted by some algebraic simplifications:

$$
A T C=\frac{1}{T}\left[C_{3}+\left(\frac{a \theta-b}{\theta^{2}}+\frac{b T}{\theta}\right)\left(\frac{2 h}{\theta}+\frac{g T^{2}}{\theta}-\frac{g T^{3}}{3}\right)+C_{2}(q-\eta)\left(\frac{3 b T^{2}}{2}\right)\right] .
$$

Also

$$
\begin{aligned}
& \quad Q=\left(a-\frac{b}{\theta}\right)\left(\frac{e^{\theta T}-1}{\theta}\right)+\left(\frac{b T}{\theta}\right) e^{\theta T}=a T-\frac{b T}{\theta}+\frac{b T}{\theta}+b T^{2}=a T+b T^{2}, \\
& \frac{d(A T C)}{d t}= \\
& =\frac{1}{T}\left[\left(\frac{a \theta-b}{\theta^{2}}+\frac{b T}{\theta}\right)\left(\frac{2 g T}{\theta}-g T^{2}\right)+\left(\frac{b}{\theta}\right)\left(\frac{2 h}{\theta}+\frac{g T^{2}}{\theta}-\frac{g T^{3}}{3}\right)+C_{2}(1-\eta)(3 b T)\right] \\
& -\frac{1}{T^{2}}\left[C_{3}+\left(\frac{a \theta-b}{\theta^{2}}+\frac{b T}{\theta}\right)\left(\frac{2 h}{\theta}+\frac{g T^{2}}{\theta}-\frac{g T^{3}}{3}\right)+C_{2}(1-\eta)\left(\frac{3 b T^{2}}{2}\right)\right], \\
& \frac{d^{2}(A T C)}{d T^{2}}= \\
& =\frac{1}{T}\left[\left(\frac{a \theta-b}{\theta^{2}}+\frac{b T}{\theta}\right)\left(\frac{2 g}{\theta}-2 g T\right)+\left(\frac{b}{\theta}\right)\left(\frac{2 g T}{\theta}-g T^{2}\right)\right. \\
& \left.+\left(\frac{b}{\theta}\right)\left(\frac{2 g T}{\theta}-g T^{2}\right)+3 b C_{2}(1-\eta)\right] \\
& -\frac{1}{T^{2}}\left[\left(\frac{a \theta-b}{\theta^{2}}+\frac{b T}{\theta}\right)\left(\frac{2 g T}{\theta}-g T^{2}\right)+\left(\frac{b}{\theta}\right)\left(\frac{2 h}{\theta}+\frac{g T^{2}}{\theta}-\frac{g T^{3}}{3}\right)+C_{2}(1-\eta)(3 b T)\right] \\
& -\frac{1}{T^{2}}\left[\frac{b}{\theta}\left(\frac{2 h}{\theta}+\frac{g T^{2}}{\theta}-\frac{g T^{3}}{3}\right)+\left(\frac{a \theta-b}{\theta^{2}}+\frac{b T}{\theta}\right)\left(\frac{2 g T}{\theta}-g T^{2}\right)+C_{2}(1-\eta) 3 b T\right] \\
& +\frac{2}{T^{3}}\left[C_{3}+\left(\frac{a \theta-b}{\theta^{2}}+\frac{b T}{\theta}\right)\left(\frac{2 h}{\theta}+\frac{g T^{2}}{\theta}-\frac{g T^{3}}{3}\right)+C_{2}(1-\eta)\left(\frac{3 b T^{2}}{2}\right)\right] .
\end{aligned}
$$

The objective is to compute the optimum value of $T$ so that the cost function $A T C$ attains its minimum value. That value of $T$, for which the total cost ATC is minimized, is the solution of the equation:

$$
\frac{d(A T C)}{d T}=0,
$$


An inventory planning problem for time-varying linear demand and parabolic holding cost with salvage value193

satisfying the sufficient condition:

$$
\frac{d^{2}(A T C)}{d T^{2}}>0
$$

The optimum solution of equation (7) is determined by applying software MATHEMATICA.

\section{Algorithm}

To determine the solution, the following algorithm is adopted:

Step 1. Initialize the problem and parameters.

Input: the numerical values of input parameters;

Step 2. Determine the value of $T$, by using equation (11)

Step 4. Check the convexity for optimality of $T$ by equation (12);

Step 5. Determine the optimal value of $Q$, and minimum value of $A T C$.

Step 6. Output: minimum total cost.

\section{Numerical experimentation}

Example 1. (Small Data) Consider the input parameter values, in proper units, as: $C_{1}(t)=$ $h+g t^{2}$ for $h=3, g=0.6, C_{2}=12, C_{3}=120, \theta=0.06, \eta=0.05, R(t)=a+b t$ for $a=20$, and $b=0.5$. Applying the above algorithm, we obtain the optimal solution for (7) as:

$$
\begin{aligned}
A T C & =\frac{1}{T}\left[120+\left(\frac{20 \cdot 0.06-0.5}{0.06^{2}}+\frac{0.5 T}{0.06}\right) \cdot\left(\frac{2 \cdot 3}{0.06}+\frac{0.06 T^{2}}{0.06}-\frac{0.6 \cdot T^{3}}{3}\right)\right. \\
& \left.+12 \cdot(1-0.05) \cdot\left(\frac{3 \cdot 0.5 \cdot T^{2}}{2}\right)\right],
\end{aligned}
$$

$T=2.9955 ; Q=64.3965 ; A T C=13568.8$. And, $\frac{d^{2}(A T C)}{d T^{2}}>0$ which implies the convexity of the function $A T C$.

Example 2. (Medium Data) Consider the input parameter values, in proper units, as: $C_{1}(t)=h+g t^{2}$ for $h=4, g=0.9, C_{2}=30, C_{3}=140, \theta=0.08, \eta=0.1, R(t)=a+b t$ for $a=30$, and $b=0.7$. Applying the above algorithm, we obtain the optimal solution for (7) as:

$$
\begin{aligned}
A T C & =\frac{1}{T}\left[140+\left(\frac{30 \cdot 0.08-0.7}{0.08^{2}}+\frac{0.7 \cdot T}{0.08}\right) \cdot\left(\frac{2 \cdot 4}{0.08}+\frac{0.9 T^{2}}{0.08}-\frac{0.9 \cdot T^{3}}{3}\right)\right. \\
& \left.+30 \cdot(1-0.1) \cdot\left(\frac{3 \cdot 0.7 \cdot T^{2}}{2}\right)\right],
\end{aligned}
$$

$T=2.9547 ; Q=94.7522 ; A T C=18921.50$. And $\frac{d^{2}(A T C)}{d T^{2}}>0$ which implies the convexity of the function $A T C$.

Example 3. (Large Data) Consider the input parameter values, in proper units, as: $C_{1}(t)=$ $h+g t^{2}$ for $h=6, g=1.4, C_{2}=60, C_{3}=180, \theta=0.09, \eta=0.7, R(t)=a+b t$ for $a=40$, and 
$b=1.2$. Applying the above algorithm, we obtain the optimal solution for (7) as:

$$
\begin{aligned}
A T C & =\frac{1}{T}\left[180+\left(\frac{40 \cdot 0.09-1.2}{0.09^{2}}+\frac{1.2 \cdot T}{0.09}\right) \cdot\left(\frac{2 \cdot 6}{0.09}+\frac{1.4 \cdot T^{2}}{0.09}-\frac{1.4 \cdot T^{3}}{3}\right)\right. \\
& \left.+60 \cdot(1-0.7) \cdot\left(\frac{3 \cdot 1.2 \cdot T^{2}}{2}\right)\right]
\end{aligned}
$$

$T=2.8506 ; Q=123.7750 ; A T C=29348.40$. And $\frac{d^{2}(A T C)}{d T^{2}}>0$ which implies the convexity of the function $A T C$.

\section{Particular cases}

Case 1: Constant demand rate. We take $b=0$ in the demand rate $R(t)=a+b t$, and we obtain constant demand rate $R(t)=a$. Thereby

$$
A T C=\frac{1}{T}\left[C_{3}+\left(\frac{a}{\theta}\right)\left(\frac{2 h}{\theta}+\frac{g T^{2}}{\theta-\frac{g T^{3}}{3}}\right)\right] .
$$

\section{Case 2: Constant holding cost}

$$
A T C=\frac{1}{T}\left[C_{3}+\left(\frac{a \theta-b}{\theta^{2}}+\frac{b T}{\theta}\right)\left(\frac{2 h}{\theta}-\frac{g T^{3}}{3}\right)+C_{2}(1-\eta)\left(\frac{3 b T^{2}}{2}\right)\right] .
$$

Case 3: No salvage

$$
A T C=\frac{1}{T}\left[C_{3}+\left(\frac{a \theta-b}{\theta^{2}}+\frac{b T}{\theta}\right)\left(\frac{2 h}{\theta}+\frac{g T^{2}}{\theta}-\frac{g T^{3}}{3}\right)+C_{2}\left(\frac{3 b T^{2}}{2}\right)\right] .
$$

\section{Sensitivity test and graphical representations}

To test the flexibility of the model, we observe the impact of changes in different parameters against average total cost. The values of each parameter are changed by $40 \%, 20 \%,-20 \%$ and $-40 \%$, treating only one parameter at a time, while maintaining the remaining parameters unaltered. The obtained results are depicted in Table 2 below:

Additionally, we verify the convexity of average total cost function by plotting the graphs (Figure 1, Figure 2 and Figure 3).

\section{Observations and discussion}

Carefully analyzing the sensitivity test Table 2, we observing the following points:

(1) Effect due to change in holding cost parameter $(h)$ : The cycle time $T$, optimal order quantity $Q$, and the average total cost $A T C$ increase as the holding cost parameter $h$ increases (Figure 4).

(2) Effect due to change in holding cost parameter $(g)$ : The cycle time $T$, and optimal order quantity $Q$ decrease as the holding cost parameter $g$ increases. While the average total cost ATC increases as the holding cost parameter $g$ increases. 
An inventory planning problem for time-varying linear demand and parabolic holding cost with salvage value195

\begin{tabular}{|c|c|c|c|c|c|}
\hline \multicolumn{3}{|c|}{ INPUT DATA } & \multicolumn{3}{|c|}{ OUTPUT DATA } \\
\hline Parameter & Change in parameter (\%) & Parameter value & $T$ & $Q$ & $A T C$ \\
\hline \multirow{4}{*}{$h=3$} & -40 & 1.80 & 2.3500 & 47.7613 & 10329.0 \\
\hline & -20 & 2.40 & 2.6962 & 57.5587 & 12036.70 \\
\hline & +20 & 3.60 & 3.2722 & 70.7976 & 14975.50 \\
\hline & +40 & 4.20 & 3.5221 & 76.6446 & 16286.90 \\
\hline \multirow{4}{*}{$g=0.6$} & -40 & 0.36 & 3.8276 & 83.8773 & 10777.60 \\
\hline & -20 & 0.48 & 3.3370 & 72.3078 & 122262.0 \\
\hline & +20 & 0.72 & 2.7486 & 58.7494 & 14749.60 \\
\hline & +40 & 0.84 & 2.5525 & 54.3076 & 15835.0 \\
\hline \multirow{4}{*}{$C_{2}=12$} & -40 & 7.2 & 3.0017 & 64.5391 & 13558.0 \\
\hline & -20 & 9.6 & 3.0006 & 64.5138 & 13563.70 \\
\hline & +20 & 14.4 & 2.9983 & 64.4609 & 13573.90 \\
\hline & +40 & 16.8 & 2.9972 & 64.4356 & 13579.10 \\
\hline \multirow{4}{*}{$C_{3}=120$} & -40 & 72 & 2.9959 & 64.4057 & 13552.80 \\
\hline & -20 & 96 & 2.9977 & 64.4471 & 13560.80 \\
\hline & +20 & 144 & 3.0012 & 64.5276 & 13576.80 \\
\hline & +40 & 168 & 3.0030 & 64.5690 & 13584.80 \\
\hline \multirow{4}{*}{$\theta=0.06$} & -40 & 0.036 & 2.7167 & 58.0242 & 21884.70 \\
\hline & -20 & 0.048 & 2.9030 & 62.2737 & 17919.80 \\
\hline & +20 & 0.072 & 3.0728 & 66.1770 & 10368.40 \\
\hline & +40 & 0.084 & 3.1386 & 67.6974 & 8097.84 \\
\hline \multirow{4}{*}{$a=20$} & -40 & 12 & 2.5598 & 54.4723 & 5291.77 \\
\hline & -20 & 16 & 2.8608 & 61.3081 & 9455.55 \\
\hline & +20 & 24 & 3.0807 & 66.3594 & 17664.90 \\
\hline & +40 & 28 & 3.1344 & 67.6002 & 21753.10 \\
\hline \multirow{4}{*}{$b=0.5$} & -40 & 0.3 & 3.1860 & 68.7953 & 16333.50 \\
\hline & -20 & 0.4 & 3.0977 & 66.7519 & 14957.80 \\
\hline & +20 & 0.6 & 2.8885 & 61.9417 & 12163.40 \\
\hline & +40 & 0.7 & 2.7605 & 59.0202 & 10736.80 \\
\hline \multirow{4}{*}{$\eta=0.05$} & -40 & 0.03 & 2.9993 & 64.4819 & 13569.30 \\
\hline & -20 & 0.04 & 2.9994 & 64.4862 & 13569.10 \\
\hline & +20 & 0.06 & 2.9995 & 64.4885 & 13568.50 \\
\hline & +40 & 0.07 & 2.9996 & 64.4908 & 13568.30 \\
\hline
\end{tabular}

Table 2: Sensitivity test (Example 1)

(3) Effect due to change in purchasing cost $\left(C_{2}\right)$ : The cycle time $T$, and optimal order quantity $Q$ slightly decrease as the purchasing $\operatorname{cost} C_{2}$ increases. While the average total cost $A T C$ slightly increases as the purchasing cost $C_{2}$ increases.

(4) Effect due to change in ordering cost $\left(C_{3}\right)$ : The cycle time $T$, optimal order quantity $Q$, and the average total cost $A T C$ increase slightly as the ordering cost parameter $C_{3}$ increases.

(5) Effect due to change in deterioration $(\theta)$ : The cycle time $T$ and optimal order quantity $Q$ increase as the deterioration $\theta$ increases. While the average total cost $A T C$ decreases as the deterioration $\theta$ increases.

(6) Effect due to change in demand constant (a): The cycle time $T$, order quantity $Q$, and total cost $A T C$ increase as demand constant a increases. 


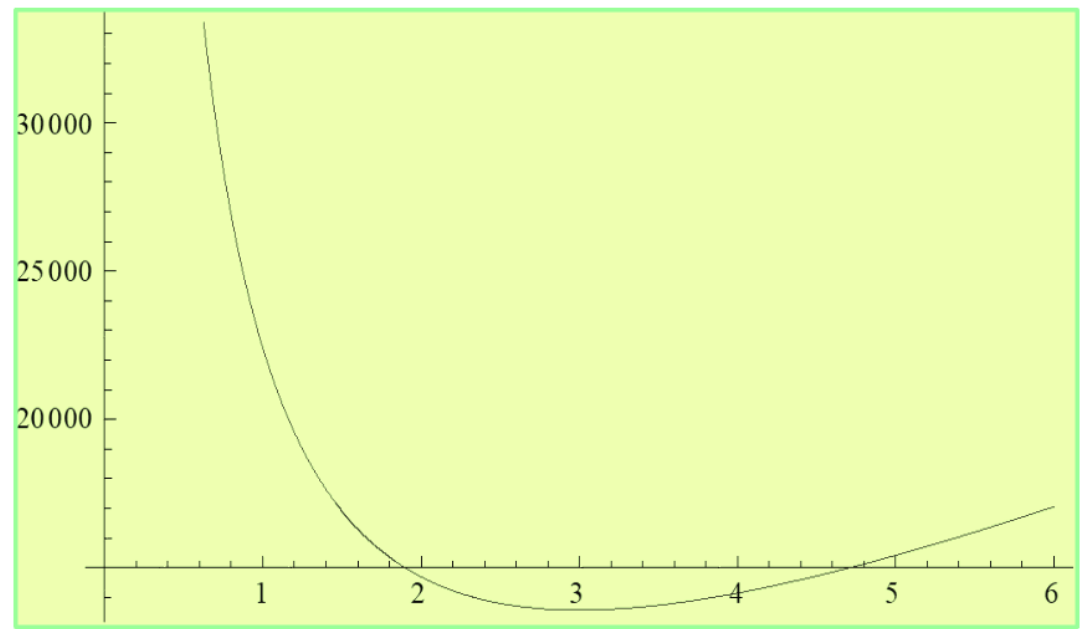

Figure 1: Convexity of average cost function ATC (Example 1)

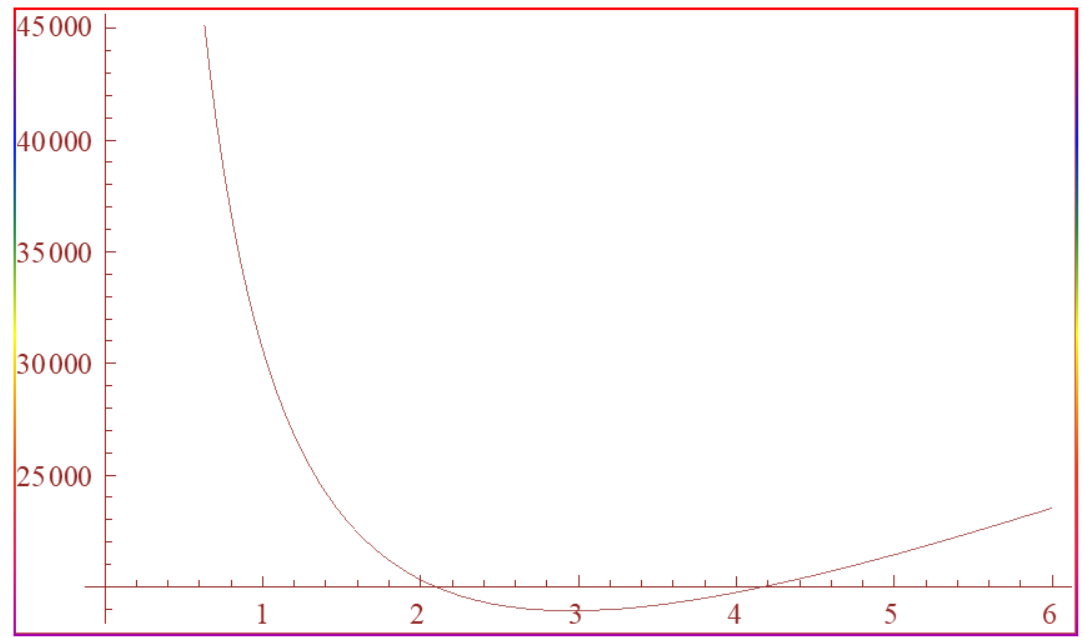

Figure 2: Convexity of average cost function ATC (Example 2)

(7) Effect due to change in demand constant (b): The cycle time $T$, optimal order quantity $Q$, and the average total cost $A T C$ decrease as the demand constant $b$ increases.

(8) Effect due to change in salvage coefficient $(\eta)$ : The cycle time $T$ and optimal order quantity $Q$ increase as the salvage coefficient $\eta$ increases. While the average total cost $A T C$ slightly decreases as the salvage coefficient $\eta$ increases. Additionally, the deterioration is the most sensitive parameter, while the salvage coefficient $\eta$ is the least sensitive parameter.

\section{Conclusions and future research scope}

In this study, a deterministic inventory model for time-dependant linear demand and parabolic holding cost with no shortages is presented. Salvage value is also incorporated in the model. An expression for average total cost function is derived. Additionally, for its practical applications, we illustrated three numerical examples conducting a test for sensitivity. All calculation works in all the three numerical examples are performed by applying the computer packages LINGO. The 
An inventory planning problem for time-varying linear demand and parabolic holding cost with salvage value197

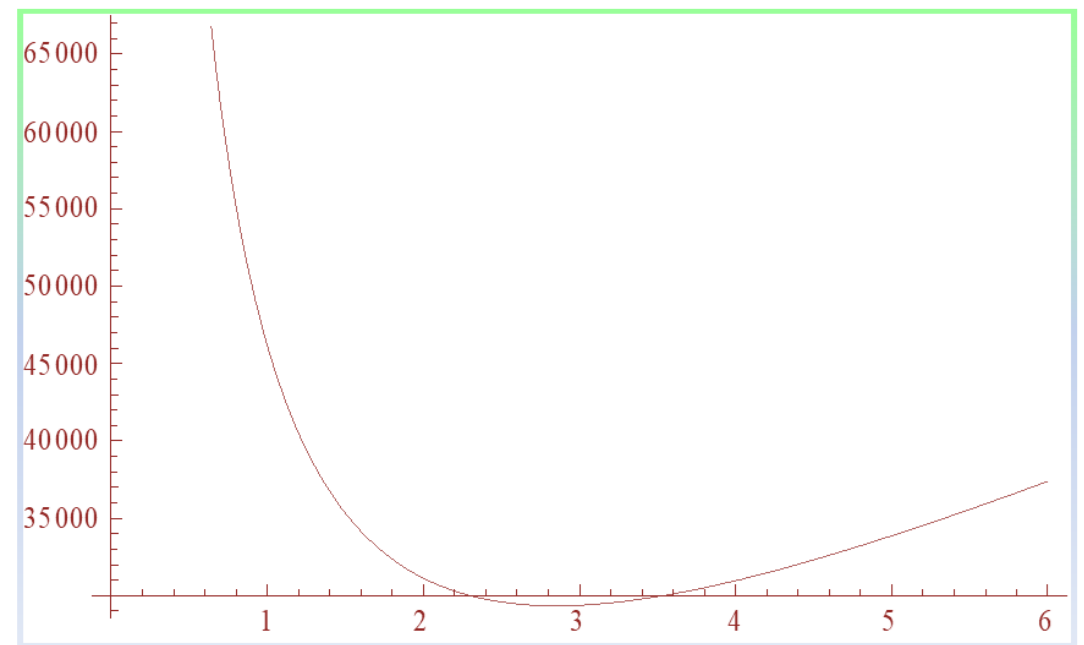

Figure 3: Convexity of average cost function ATC (Example 3)
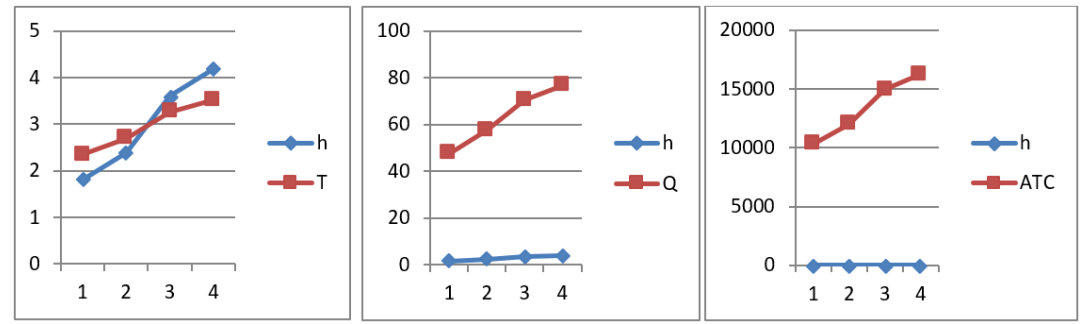

Figure 4: Effect of variation of $h$ to $T, Q$, and $A T C$

obtained results are discussed, and demonstrates that the effect of variation of rate of changes of the demand constants ( $a$ and $b$ ), and ordering cost on the inventory system behavior is the most significant. Additionally, the salvage coefficient $\eta$ possess the least impact on the parameters of the system. The model is suggested to the industries and retailers to determine accurately the optimal value of average total cost. The proposed model might be useful in dealing with the problems of seasonal products, because of the tendency of demand rate and salvage value. This manuscript may be further extended for permitting shortages, freight charges and advertisement costs. Stochastic nature of demand may also be another direction for future research.

\section{Acknowledgement}

The author is very grateful to the editor(s), and would like to thank the reviewers for their valuable suggestions and comments.

\section{References}

[1] Alfares, H. K. (2007). Inventory model with stock-level dependent demand rate and variable holding cost. International Journal of Production Economics, 108, 259-265. doi:10.1016/j.ijpe.2006.12.013

[2] Begum, R., Sahu, S. K., and Sahoo, R. R. (2010). An EOQ model for deteriorating items with Weibull distribution deterioration, unit production cost with quadratic demand and shortages. Applied Mathematical Sciences, 4, 271-288. http://www.m-hikari.com/ams/ams-2010/ams-5-82010/sahooAMS5-8-2010.pdf 
[3] Bhandari, R. M., and Sharma, S. K. (2000). A single period inventory problem with quadratic demand distribution under the influence of market policies. Engineering Science, 12(2), 117-127. https://pdfs.semanticscholar.org/13a4/c74d3ef0d15a5113a83511d284d15edc1566.pdf

[4] Bhunia, A. K., and Shaikh, A. A. (2016). Investigation of two-warehouse inventory problems in interval environment under inflation via particle swarm optimization. Mathematical and Computer Modelling of Dynamical Systems, 22(2), 160-179. doi:10.1080/13873954.2016.1150860

[5] Chu, P., Chung, K. J., and Lan, S. P. (1998). Economic order quantity of deteriorating items under permissible delay in payments. Computers and Operations Research, 25, 817-824. doi:10.1016/S0305-0548(98)00006-9

[6] Chang, H., and Dye, C. (1999). An EOQ model for deteriorating items with time varying demand and partial backlogging. Journal of the Operational Research Society, 50, 1176-1182. doi:10.1057/palgrave.jors.2600801

[7] Chang, H. J., Dye, C. Y., and Chung, B. R. (2002). An inventory model for deteriorating items under the condition of permissible delay in payments. Yugoslav journal of Operations Research, $12,73-84$.

[8] Chung, K. J., Chang, S. L., and Yang, W. D. (2001). The optimal cycle time for exponentially deteriorating products under trade credit financing. The Engineering Economist, 46, 232-242. doi:10.1080/00137910108967575

[9] Dutta, D., and Kumar, P. (2015a). Application of fuzzy goal programming approach to multiobjective linear fractional inventory model. International Journal of Systems Science, 46(12), 22692278. doi:10.1080/00207721.2013.860639

[10] Dutta, D., and Kumar, P. (2015b). A partial backlogging inventory model for deteriorating items with time-varying demand and holding cost: An interval number approach. Croatian Operational Research Review, 6(2), 321-334. doi:10.17535/crorr.2015.0025

[11] Dutta, D., and Kumar, P. (2015c). A partial backlogging inventory model for deteriorating items with time-varying demand and holding cost. International Journal of Mathematics in Operations Research, 7(3), 281-296. doi:10.1504/IJMOR.2015.069144

[12] Ghare, P. M., and Schrader, G. H. (1963). A model for exponentially decaying inventory system. Journal of Industrial Engineering, 163, 238-243.

[13] Hwang, H., and Shinn, S. W. (1997). Retailer's pricing and lot-sizing policy for exponentially deteriorating products under the condition of permissible delay in payments. Computers and Operation Research, 24, 539-547. doi:10.1016/S0305-0548(96)00069-X

[14] Khanra, S., and Chaudhuri, K. S. (2003). A note on order level inventory model for a deteriorating item with timedependent quadratic demand. Computers and Operations Research, 30, 1901-1916. doi:10.1016/S0305-0548(02)00113-2

[15] Khanra, S., Ghosh, S. K., and Chaudhuri, K. S. (2011). An EOQ model for a deteriorating item with time dependent quadratic demand under permissible delay in payments. Applied Mathematics and Computation, 62(4), 1-9. doi:10.1016/j.amc.2011.04.062

[16] Kumar, P., and Dutta, D. (2015). Multi-objective linear fractional inventory model of multiproducts with price-dependant demand rate in fuzzy environment. International Journal of Mathematics in Operations Research, 7(5), 547-565. doi:10.1504/IJMOR.2015.071280

[17] Kumar, P. (2016). Multi criteria decision making in inventory models by fuzzy approaches, Publisher: Scholars' Press, Germany.

[18] Kumar, P., and Keerthika, P. S. (2018). An inventory model with variable holding cost and partial backlogging under interval uncertainty: Global criteria method. International Journal of Mechanical Engineering and Technology, 9(11), 1567-1578.

[19] Kumar, P. (2019). Inventory optimization model for quadratic increasing holding cost and linearly increasing deterministic demand. International Journal of Recent Technology and Engineering, 7(6), 1999-2004. https://www.ijrte.org/wp-content/uploads/papers/v7i6/F2700037619.pdf

[20] Muhlemann, A. P., and Valtis-Spanopoulos, N. P. (1980). A variable holding cost rate EOQ model. European Journal of Operational Research, 4, 132-135. doi:10.1016/0377-2217(80)90022-3

[21] Mishra, V. K. (2012). Inventory model for time dependent holding cost and deterioration with salvage value and shortages. The Journal of Mathematics and Computer Science, 4(1), 37-47. doi:10.22436/jmcs.04.01.06

[22] Mishra, U. (2016). An inventory model for two parameter Weibull deterioration and declining 
demand under shortages, Journal of Information and Optimization Sciences, 37(4), 511-533. doi:10.1080/09720510.2015.1086152

[23] Ouyang, L.-Y., Wu, K.-S., and Cheng, M.-C. (2005). An inventory model for deteriorating items with exponential declining demand and partial backlogging. Yugoslav Journal of Operations Research, 15(2), 277-288. https://core.ac.uk/download/pdf/26928979.pdf

[24] Pando, V, San-José, L. A., Garcı-Laguna, J., and Sicilia, J. (2013). An economic lot-size model with non-linear holding cost hinging on time and quantity. International Journal of Production Economics, 145(1), 294-303. doi:10.1016/j.ijpe.2013.04.050

[25] Rangavajhala Venkateswarlu, and Mohan, R. (2013). An inventory model for time varying deterioration and price dependent quadratic demand with salvage value. Journal of Computational and Applied Mathematics, 1(1), 21-27.

[26] Sharma, A. K., Kumar, M., and Ramani, N. (2012). An inventory model with weibull distribution deteriorating item power pattern demand with shortage and time dependent holding cost. American Journal of Applied Mathematics and Mathematical Sciences, 1(2), 17-22. http://www.mhikari.com/ams/ams-2010/ams-41-44-2010/mishraAMS41-44-2010-1.pdf

[27] Tripathi, R. P., Singh, D., and Aneja, S. (2018). Inventory models for stock-dependent demand and time varying holding cost under different trade credits. Yugoslav Journal of Operations Research, 28(1), 139- 151. doi:10.2298/YJOR160317018T

[28] Tripathi, R. P., and Tomar, S. S. (2018). Establishment of EOQ Model with Quadratic TimeSensitive Demand and Parabolic-Time Linked Holding Cost with Salvage Value. International Journal of Operations Research, 15(3), 135-144.

[29] Weiss, H. J. (1982). Economic order quantity models with non-linear holding cost. European Journal of Operational Research, 9, 56-60. doi:10.1016/0377-2217(82)90010-8 